\title{
Stunting and its determinant factors among children aged 6-59 months in Ethiopia
}

Amare Tariku', Gashaw Andargie Biks ${ }^{2}$, Terefe Derso ${ }^{1 *}$, Molla Mesele Wassie ${ }^{1}$ and Solomon Mekonnen Abebe ${ }^{1}$

\begin{abstract}
Background: Though Ethiopia has implemented different nutritional interventions, childhood stunting on which literature is limited continues as a severe public health problem. Thus, this study aimed to investigate stunting and its determinants among children aged 6-59 months in the predominantly rural northwest Ethiopia.

Methods: A community based cross-sectional study was conducted from May to June 2015 at Dabat Health and Demographic Surveillance System (HDSS) site. A total of 1295 mother-child pairs were included for analysis. An ordinal multivariable logistic regression analysis was carried out to identify the determinants of severe stunting. To show the strength of associations, both Crude Odds Ratio (COR) and Adjusted Odds Ratios (AOR) with a 95\% Confidence Interval (Cl) were estimated. Also, a $P$-value of $<0.05$ was used to declare statistical significance in the final model.

Results: The overall prevalence of stunting among children aged 6-59 months was $64.5 \%$, of which about $37.7 \%$ and $26.8 \%$ were moderately and severely stunted, respectively. Farming occupation of mother [AOR $=1.45 ; 95 \% \mathrm{Cl}: 1.08$, 1.93], lack of postnatal vitamin-A supplementation [AOR $=1.54 ; 95 \%: 1.19,2.00]$, poorer household wealth status $[\mathrm{AOR}=2.07 ; \mathrm{Cl}: 1.56,2.75]$ and accessing family food from farms [AOR $=1.44 ; 95 \% \mathrm{Cl}: 1.09,1.89]$ were identified as the key determinants of severe stunting.

Conclusion: In the district, the magnitude of stunting was a critical public health concern. Therefore, emphasis should be given to improving mothers' postnatal vitamin A supplementation coverage and building knowledge about appropriate child feeding practices among farmer mothers and poorer households.
\end{abstract}

Keywords: Stunting, Children, Health and demographic surveillance system, Ethiopia

\section{Background}

Stunting, low Height-for-Age Z-score (HAZ) is a global public health problem, affecting linear-growth potential of children. Worldwide, it affects 165 million (26\%) children under 5 years [1]. The problem is graver in developing countries where it is the major contributor to child mortality [1, 2]. About $90 \%$ of the global stunted children live in Africa and Asia [2]; more than 40\% are found in Sub-Saharan Africa, including Ethiopia [3, 4].

Childhood stunting (linear growth failure) is related to various adverse health consequences and irreversible damages. Stunting is correlated with poor developmental

\footnotetext{
*Correspondence: dersotere@gmail.com; Terefe.Dereso@uog.edu.et ${ }^{1}$ Department of Human Nutrition, Institute of Public Health, College of Medicine and Health Sciences, University of Gondar, Gondar, Ethiopia Full list of author information is available at the end of the article
}

attainment [5] and intelligence in children [6, 7]. It is also documented that stunted children are less likely to be enrolled in school [8]. The risk of mortality and susceptibility to infections are also high among stunted children [1]. The consequences of child stunting also extend to adulthood. As an illustration, diminished productivity $[7,8]$, increased risk of excess weight gain and chronic non-communicable diseases in later life were frequently reported by earlier investigations $[9,10]$. Moreover, stunting is a matter of great concern in terms of increased obstetric risks [7].

As the cause of stunting is complex and intertwined it needs further investigations because optimal child growth requires adequate nutrient supply and health appropriate care [11]. Earlier studies showed that feeding habits, health and socio-economic characteristics were 
significant determinants of child stunting. Inappropriate feeding practice, such as pre-lacteal feeding [12], nonexclusive breastfeeding, bottle feeding [13], low meal frequency and dietary diversity [14-16] as well as early or late initiation of complementary feeding [17] are significantly associated with stunting. Male sex [14] and frequent diarrheal episodes [12, 18] also increase the likelihood of stunting. Linear growth failure is documented in children whose mothers are illiterate, [19], old [19], work out of home [13, 19] and take no prenatal iron supplementation [15]. In addition, large family size and multiple siblings [13, 20, 21], food insecurity, poor wealth status, inadequate health care utilization and sanitary practices $[17,20,22-26]$, unavailability of latrines $[21,27]$ and use of unprotected sources of drinking water [28] are the socio-economic determinates of stunting.

Despite a marked decline in the burden of undernutrition, stunting persisted as a severe public health problem in developing countries [1, 4, 29]. Also, nearly half (45\%) of child mortality is associated with undernutrition [1]. In Ethiopia, a considerable numbers of such nutritional arrangements as the national nutritional program and the Infant and Young Child feeding Strategy were implemented in the last decades in order to protect children from the maladies of undernutrition [30,31]. However, the burden of stunting remains a public health concern $[4,29]$. Similarly, inappropriate maternal and child feeding practices are common in the country $[4,29]$. Most pregnant and lactating mothers are suffering from different micronutrient deficiencies which affect the growth of fetuses and infants, respectively. Thus, the postnatal period is a window of opportunity to improve mothers' micronutrient status, including the breast milk retinol level, through supplementation and other dietary approaches [32]. Thus, investigating the determinants of childhood stunting is of a paramount importance to design strategies to address the problem. However, literature is limited and even the available reports do not show the effect of independent variables on the level (severity) of stunting. Therefore, this study aimed to investigate stunting and associated factors among children aged 6-59 months using the ordinal logistic regression model.

\section{Methods}

\section{Study setting}

A community-based cross-sectional study was conducted from May to June 2015 at Dabat Health and Demographic Surveillance System (HDSS) site located in Dabat District, northwest Ethiopia. The livelihood of the inhabitants mainly depends on subsistence farming. The HDSS covers 67,385 people living in thirteen kebeles (smallest administration unit in Ethiopia), nine of which are rural.

\section{Sampling procedure}

This study is part of a bigger survey entitled 'Child Nutritional Status and Feeding Practice'. In the survey, eight kebeles were randomly selected from the total thirteen of the HDSS site. All children (6-59 months) living in these kebeles were included in the survey. Sample size was determined using Epi-info version 3.7 by considering the following assumptions; the prevalence of stunting in Amhara Region as 52\% [4], 95\% level of confidence, $5 \%$ margin of error, $10 \%$ non-response rate, and a design effect of 2 . Thus, a minimum sample size of 844 was obtained. To improve the power of the study, 1295 children fulfilling the inclusion criteria were included in the study.

\section{Data collection and analysis}

A structured interviewer-administered questionnaire was used to collect data. The English version questionnaire was translated to the national and local language. A pretest was done out of the study area before the actual data collection. A total of fourteen data collectors and three field supervisors were involved in the data collection. Training was given to data collectors and supervisors for 2 days.

The anthropometric assessment was done according to the standardized procedures stipulated by the Food and Nutrition Technical Assistance (FANTA) 'Anthropometric Indicators Measurement Guide' [33]. Height was measured using the seca vertical height scale (German, Serial No. 0123) standing upright in the middle of the board. The child's head, shoulders, buttocks, knees, and heels touched the vertical board. The length of a child (aged 6-23 months) was measured using a horizontal wooden length board in recumbent position and read to the nearest $0.1 \mathrm{~cm}$.

Anthropometric related data were transferred to the WHO Anthro-Plus software version 1.0.4 using Stat/ Transfer version 9. The Z-scores of indices, Height-forAge Z-scores (HAZ), were calculated using the WHO Multicenter Growth Reference Standard. The child was classified as severely stunted if his/her Z-score was less than -3 Standard Deviation (SD), moderately stunted $(-3.00 \leq \mathrm{HAZ}<2)$; otherwise he/she was defined as wellnourished if Z-score $\geq-2$ SD [34].

Dietary diversity score (DDS) of a child was assessed by interviewing the mother to list all food and drink taken by the child in the $24 \mathrm{~h}$ preceding the survey. In case of mixed dish, the data collectors assisted mothers to list the ingredients of the food items, and using the standardized DDS tool, food items were categorized into seven food groups [35]. The DDS of four is considered as the minimum acceptable dietary diversity; accordingly a child with a DDS of less than four was classified as having poor dietary diversity; otherwise, it was considered to have good dietary diversity. 
Table 1 Socio-demographic and economic characteristics of children (6-59 months) and their parents in the predominantly rural population of northwest Ethiopia, 2015

\begin{tabular}{|c|c|c|}
\hline Characteristics & Frequency & Percent \\
\hline \multicolumn{3}{|l|}{ Child age (in months) } \\
\hline $6-11$ & 196 & 15.1 \\
\hline $12-35$ & 706 & 54.6 \\
\hline $36-47$ & 253 & 19.5 \\
\hline $48-59$ & 140 & 10.8 \\
\hline Mean age $( \pm \mathrm{SD})$ & $27.9( \pm 14.0)$ & \\
\hline \multicolumn{3}{|l|}{ Sex of child } \\
\hline Female & 639 & 49.3 \\
\hline Male & 656 & 50.7 \\
\hline \multicolumn{3}{|l|}{ Head of the household } \\
\hline Female & 45 & 3.5 \\
\hline Male & 1250 & 96.5 \\
\hline \multicolumn{3}{|l|}{ Mothers age } \\
\hline $15-34$ years & 737 & 56.9 \\
\hline $35-50$ years & 558 & 43.1 \\
\hline \multicolumn{3}{|l|}{ Marital status } \\
\hline Currently unmarried & 149 & 11.5 \\
\hline Currently married & 1146 & 88.5 \\
\hline \multicolumn{3}{|l|}{ Religion } \\
\hline Orthodox Christianity & 1220 & 94.2 \\
\hline Others $^{\mathrm{a}}$ & 75 & 5.8 \\
\hline \multicolumn{3}{|l|}{ Household size } \\
\hline$\leq 4$ & 470 & 36.3 \\
\hline $5-7$ & 632 & 48.8 \\
\hline $8-10$ & 193 & 14.8 \\
\hline \multicolumn{3}{|c|}{ Number of children under five } \\
\hline 1 & 101 & 7.8 \\
\hline $2-4$ & 1194 & 92.2 \\
\hline \multicolumn{3}{|l|}{ Maternal education } \\
\hline No formal education & 884 & 68.3 \\
\hline Primary education & 189 & 14.6 \\
\hline Secondary education & 222 & 17.1 \\
\hline \multicolumn{3}{|c|}{ Maternal employment status } \\
\hline Housewife & 728 & 56.2 \\
\hline Farmer & 351 & 27.1 \\
\hline Others $^{b}$ & 216 & 16.7 \\
\hline \multicolumn{3}{|l|}{ Paternal education } \\
\hline No formal education & 864 & 66.7 \\
\hline Formal education & 431 & 33.3 \\
\hline \multicolumn{3}{|c|}{ Main source of family food } \\
\hline Own production & 886 & 68.4 \\
\hline Purchasing & 364 & 28.1 \\
\hline
\end{tabular}

Table 1 Socio-demographic and economic characteristics of children (6-59 months) and their parents in the predominantly rural population of northwest Ethiopia, 2015 (Continued)

\begin{tabular}{lll}
\hline Characteristics & Frequency & Percent \\
\hline \multicolumn{1}{c}{ Others } & \\
Wealth status & 45 & 3.5 \\
$\quad$ Poor & 489 & \\
$\quad$ Medium & 387 & 37.8 \\
$\quad$ Rich & 419 & 29.9 \\
Health care access & & 32.4 \\
Good & 1148 & \\
$\quad$ Poor & 147 & 88.6 \\
$\begin{array}{l}\text { a Muslim and protestant Christianity } \\
\text { bPrivate business, students, servant, unemployed } \\
\text { 'Food donating from government and families }\end{array}$ & 11.4 \\
\hline
\end{tabular}

Data were entered into Epi-info version 3.5.3 and analyzed by using Stata version 12. Tables and graphs were used to present data, while frequencies and proportions were used to summarize the variables. The household wealth index was computed using a composite indicator for urban and rural residents by considering properties like, selected household assets and size of agricultural land. Using Principal Component Analysis (PCA), the factor score was summed and ranked into poor, medium, and rich. The ordinal logistic regression model was used to identify the determinants of severe stunting. A bivariable analysis was carried out to see the crude effect of each independent variable on severe stunting, and after that variables with $P$-values of $<0.2$ in the bivariable analysis were entered into the multivariable analysis. To show the strength of association, Adjusted Odds Ratio (AOR) with a 95\% Confidence Interval (CI) was estimated. Also, a $P$-value of $<0.05$ was used to declare statistical significance in the final model. The parallel line assumption and the goodness-of-fit-test was checked, accordingly the model well fits the data.

\section{Results}

A total of 1295 mother-child pairs were included in the study. The mean age $( \pm \mathrm{SD})$ of children was $27.9( \pm 14.0)$ months, and $50.7 \%$ of whom were male. Nearly twothird, (56.2\%) of the mothers were housewives, whereas about $27.1 \%$ were farmers. The majority of the households had male househeads (96.5\%), and accessed food from farms $(68.4 \%)$ (Table 1).

Nearly half $(46.1 \%)$ of the mothers took prenatal iron supplementation, but only few (1.7\%) consumed extra meals during pregnancy. Furthermore, one-quarter (23.6\%) of the mothers received postnatal vitamin-A supplementation. In this community, only half $(51.5 \%$ and $51.2 \%$ ) of the mothers gave colostrum and initiated breastfeeding within an hour of delivery, respectively. 
Table 2 Maternal and child feeding practice in the predominantly rural population of northwest Ethiopia, 2015

\begin{tabular}{|c|c|c|c|c|c|}
\hline \multirow{2}{*}{$\begin{array}{l}\text { Characteristics } \\
\text { Extra food during pregnancy }\end{array}$} & \multirow[t]{2}{*}{ Frequency } & \multirow[t]{2}{*}{ Percent } & \multicolumn{3}{|c|}{ (Continued) } \\
\hline & & & Characteristics & Frequency & Percent \\
\hline Yes & 22 & 1.7 & \multicolumn{3}{|l|}{ Dairy products } \\
\hline No & 1273 & 98.3 & Yes & 302 & 23.3 \\
\hline \multicolumn{3}{|c|}{ Prenatal iron supplementation } & No & 993 & 72.7 \\
\hline Yes & 597 & 46.1 & \multicolumn{3}{|c|}{ Meat, poultry, and fish } \\
\hline No & 698 & 53.9 & Yes & 164 & 12.7 \\
\hline \multicolumn{3}{|l|}{ Colostrums } & No & 1131 & 87.3 \\
\hline Given to the child & 667 & 51.5 & \multicolumn{3}{|l|}{ Egg } \\
\hline Discarded & 626 & 48.5 & Yes & 77 & 5.9 \\
\hline \multicolumn{3}{|c|}{ Breastfeeding initiation within $1 \mathrm{~h}$} & No & 1218 & 94.1 \\
\hline Yes & 663 & 51.2 & \multicolumn{3}{|c|}{ Other fruits and vegetables } \\
\hline No & 632 & 48.8 & Yes & 17 & 1.3 \\
\hline \multicolumn{3}{|l|}{ Ever breastfed } & No & 1278 & 98.7 \\
\hline Yes & 1287 & 99.4 & \multicolumn{3}{|c|}{ Maternal vitamin A supplementation } \\
\hline No & 8 & 0.6 & Yes & 305 & 23.6 \\
\hline \multicolumn{3}{|l|}{ Exclusive breastfeeding } & No & 990 & 76.4 \\
\hline Yes & 808 & 62.4 & \multicolumn{3}{|l|}{ Deworming } \\
\hline No & 487 & 37.6 & Yes & 471 & 36.4 \\
\hline \multicolumn{3}{|l|}{ Pre-lacteal feeding } & No & 824 & 63.6 \\
\hline Yes & 369 & 28.5 & \multicolumn{3}{|c|}{ History of fever in the previous 2 weeks } \\
\hline No & 926 & 71.5 & Yes & 495 & 38.2 \\
\hline \multicolumn{3}{|c|}{ Complementary feeding initiation } & No & 800 & 61.8 \\
\hline Timely & 740 & 57.1 & \multicolumn{3}{|c|}{ History of diarrheal attack in the previous 2 weeks } \\
\hline Early & 155 & 12 & Yes & 242 & 18.7 \\
\hline Late & 400 & 30.9 & No & 1053 & 81.3 \\
\hline
\end{tabular}

Bottle feeding

Yes 63

No 1232

Dietary diversity score

$<4$ food groups $\quad 1218$

$\geq 4$ food groups $\quad 77$

Starchy staples

Yes 1190

No 105

Vitamin-A rich fruits and vegetables

Yes

No

Legumes, nuts and seeds

Yes

Oils and fats
Table 2 Maternal and child feeding practice in the predominantly rural population of northwest Ethiopia, 2015 (Continued)

Moreover, about $62.4 \%$ of children were exclusively breastfed for the optimal duration of 6 months. Regarding complementary feeding practices, only $5.9 \%$ of children consumed a complementary food made of at least four food groups. The dietary pattern of the setting consisted of $91.9 \%$ and $73.3 \%$ of starchy staples and legumes, respectively, with $1.2 \%, 5.9 \%$, and $1.3 \%$ of vitamin-A rich fruits and vegetables eggs, and other fruits and vegetables, in that order, in the $24 \mathrm{~h}$ preceding the date of the survey(Table 2).

Most (61.3\%) of the women used unprotected source of water for household consumption, and about onefourth $(26.3 \%)$ of mothers required more than $30 \mathrm{~min}$ to fetch water from the sources. Furthermore, most (92.4\%) of the respondents didn't treat water before consumption. Latrine was not available in $70.1 \%$ of the households (Table 3).

The overall prevalence of stunting (<-2HAZ) among children aged 6-59 months was 64.5\% [95\% CI; 59.4, 69.6]. About 37.7\% [95\% CI; 32.5, 42.9\%] and 26.8\% [95\% CI; 22.1, 31.5\%] of children were moderately and 
Table 3 Household related characteristics of the study participants in the predominantly rural population of northwest Ethiopia, 2015

\begin{tabular}{|c|c|c|}
\hline Characteristics & Frequency & Percent \\
\hline \multicolumn{3}{|l|}{ Source of drinking water } \\
\hline Protected source & 501 & 38.7 \\
\hline Unprotected source & 794 & 61.3 \\
\hline \multicolumn{3}{|l|}{ Time to fetch water } \\
\hline$\leq 30 \min$ & 955 & 73.7 \\
\hline$>30 \mathrm{~min}$ & 340 & 26.3 \\
\hline \multicolumn{3}{|l|}{ Water treatment } \\
\hline Not at all & 1196 & 92.4 \\
\hline Always & 68 & 5.3 \\
\hline Sometimes & 31 & 2.4 \\
\hline \multicolumn{3}{|l|}{ Availability of latrine } \\
\hline Yes & 387 & 29.9 \\
\hline No & 908 & 70.1 \\
\hline \multicolumn{3}{|l|}{ Waste disposal } \\
\hline Appropriate $^{a}$ & 160 & 12.4 \\
\hline Inappropriate ${ }^{b}$ & 1135 & 87.6 \\
\hline \multicolumn{3}{|c|}{ Hand washing before feeding } \\
\hline Not at all & 12 & 0.9 \\
\hline Sometimes & 41 & 3.2 \\
\hline Always & 1242 & 95.9 \\
\hline \multicolumn{3}{|l|}{ Hand washing after toilet } \\
\hline Not at all & 140 & 10.8 \\
\hline Sometimes & 222 & 17.1 \\
\hline Always & 933 & 72 \\
\hline
\end{tabular}

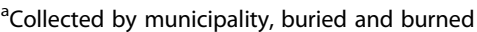

${ }^{b}$ Dumped in street/open space, compound and river

severely stunted, respectively. Besides, severe stunting was observed among $22.2 \%$ and $20.3 \%$ children whose mothers didn't receive postnatal vitamin-A supplementation and accessed family food mainly from their farms (own production), respectively (Table 4).

After controlling for potential confounders, the result of the multivariable ordinal logistic regression analysis revealed that wealth status, maternal occupation, source of family food, and postnatal maternal vitamin-A supplementation were significantly associated with severe stunting. Accordingly, the odds of severe stunting were higher among children whose mothers were farmers $[\mathrm{AOR}=1.45$; 95\% CI: $1.08,1.93]$ and didn't receive postnatal vitamin-A supplementation $[\mathrm{AOR}=1.54$; 95\%: $1.19,2.00]$. Likewise, being members of poorer households $[\mathrm{AOR}=2.07$; $\mathrm{CI}: 1.56,2.75]$ and medium wealth status households $[\mathrm{AOR}=1.37 ; 95 \% \mathrm{CI}: 1.03,1.83]$ was more associated with increased odds of childhood severe stunting than being members of richer households.
More severely stunted growth was observed among children from households which accessed family food mainly from farms (own production) than those who mainly accessed from the market, by purchasing $[\mathrm{AOR}=1.44 ; 95 \% \mathrm{CI}: 1.09,1.89]($ Table 5$)$.

\section{Discussion}

In the present study, the magnitude of overall and severe stunting among children was higher than the recent Demographic and Health Survey Reports of Ethiopia (overall stunting 44\%, severe stunting 21\%)) [4] and Nepal (overall stunting 40.6\%, severe stunting 15.9\%) [25]. The discrepancy could be explained by the depth of the studies in that the latter reports were national with larger number of children. In contrast, this study was done only in the rural areas of northwest Ethiopia. In fact, because of poor dietary habit, nutritional awareness [4], and limited allocation of health care resources $[4,36]$, stunting is more common in rural areas [37]. On the other hand, studies in developing countries claimed that stunting is less common in infants aged less than 6 months as they are on breastfeeding [38]. However due to inappropriate complementary feeding practices and increased nutritional demand, the risk of impaired linear growth becomes higher after the sixth month [39]. Therefore, the high prevalence of overall and severe stunting in this study could also be related to the exclusion of infants aged less than 6 months, while they were included in the other studies.

Similarly, our finding was higher than that of another local study in Bule Hora district, south Ethiopia (overall stunting $47.6 \%$, severe stunting 20.2\%) [12]. The difference could be related to variations in the livelihood of the inhabitants; livestock and cash crops are the major economic sources in Bule Hora, whereas it is subsistence farming in the current study area. Given that, children of the former study area might have protein-rich animal food which is protective against the risk of stunting [40].

The result of the ordinal multivariable analysis showed that the odds of being severely stunted were higher among children from poorer and medium wealth status families. This is due to the fact that compared to the better-offs poorer households are incapable of purchasing nutritionally adequate and diversified food for their children. In fact, insufficient food intake, exposure to infections, and lack of access to basic health services are associated with stunning [27]. Moreover, the finding was supported by those of previous studies in developing countries [14, 25, 27].

Also, children of farmer mothers were at higher risk of facing severely stunted growth than children of housewife mothers. Parallel findings were also reported from Southern Ethiopia [13, 19]. Obviously, outdoor worker mothers do not have enough time to care and 
Table 4 Distribution of stunting by the selected characteristics among children aged 6-59 months in the predominantly rural population of northwest Ethiopia, 2015 ( $N=1295)$

\begin{tabular}{|c|c|c|c|c|}
\hline \multirow[t]{2}{*}{ Variables } & \multicolumn{4}{|c|}{ Severity of stunting (Height-for-Age Z-score) (HAZ) } \\
\hline & Severe stunting $(\mathrm{HAZ}<-3)$ & $\begin{array}{l}\text { Moderate stunting } \\
(-3.00 \leq \mathrm{HAZ}<-2)\end{array}$ & Normal (HAZ $\geq-2)$ & Total \\
\hline \multicolumn{5}{|c|}{ Number of children under five } \\
\hline 1 & $21(1.6 \%)$ & $34(2.6 \%)$ & $46(3.6 \%)$ & $101(7.8 \%)$ \\
\hline $2-4$ & $326(25.2 \%)$ & $454(35 \%)$ & $414(32 \%)$ & 1194(92.2\%) \\
\hline \multicolumn{5}{|l|}{ Wealth status } \\
\hline Poor & $187(14.4 \%)$ & 189(14.6\%) & 113(8.7\%) & $489(37.7 \%)$ \\
\hline Medium & $90(7 \%)$ & $148(11.4 \%)$ & $149(11.5 \%)$ & $387(29.9 \%)$ \\
\hline Rich & $70(5.4 \%)$ & $151(11.7 \%)$ & 198(15.3\%) & $419(32.4 \%)$ \\
\hline \multicolumn{5}{|c|}{ Main source of family food } \\
\hline Own production & $263(20.3 \%)$ & $332(25.6 \%)$ & $291(22.5 \%)$ & $886(68.4 \%)$ \\
\hline Purchasing & $66(5.1 \%)$ & $142(10.9 \%)$ & $156(12.1 \%)$ & $364(28.1 \%)$ \\
\hline Others & $18(1.4 \%)$ & $14(1.1 \%)$ & $13(1 \%)$ & $45(3.5 \%)$ \\
\hline \multicolumn{5}{|c|}{ Maternal employment status } \\
\hline Housewife & $167(12.9 \%)$ & $285(22 \%)$ & $276(21.3 \%)$ & $728(56.2 \%)$ \\
\hline Farmer & $146(11.3 \%)$ & $122(9.4 \%)$ & $83(6.4 \%)$ & $351(27.1 \%)$ \\
\hline Others & $34(2.6 \%)$ & $81(6.3 \%)$ & $101(7.8 \%)$ & $216(16.7 \%)$ \\
\hline \multicolumn{5}{|l|}{ Health care access } \\
\hline Good & $295(22.7 \%)$ & $431(33.3 \%)$ & $422(32.6 \%)$ & $1148(88.6 \%)$ \\
\hline Poor & $52(4 \%)$ & $57(4.4 \%)$ & $38(3 \%)$ & $147(11.4 \%)$ \\
\hline \multicolumn{5}{|l|}{ Source of drinking water } \\
\hline Protected source & 138(10.7\%) & $184(14.2 \%)$ & 179(13.8\%) & $501(38.7 \%)$ \\
\hline Unprotected source & $209(16.1 \%)$ & $304(23.5 \%)$ & $281(21.7 \%)$ & $794(61.3 \%)$ \\
\hline \multicolumn{5}{|c|}{ Maternal Vitamin A supplementation } \\
\hline Yes & $59(4.6 \%)$ & $111(8.6 \%)$ & 135(10.4\%) & $305(23.6 \%)$ \\
\hline No & $288(22.2 \%)$ & $377(29.1 \%)$ & $325(25.1 \%)$ & $990(76.4 \%)$ \\
\hline \multicolumn{5}{|l|}{ Exclusive breast feeding } \\
\hline Yes & 180(13.9\%) & $315(24.3 \%)$ & $313(24.2 \%)$ & $808(62.4 \%)$ \\
\hline No & $167(12.9 \%)$ & $173(13.4 \%)$ & $147(11.3 \%)$ & 487(37.6\%) \\
\hline \multicolumn{5}{|c|}{ Complementary feeding initiation } \\
\hline Timely & $182(14.1 \%)$ & $280(21.6 \%)$ & $278(21.4 \%)$ & $740(57.1 \%)$ \\
\hline Early & $39(3 \%)$ & $59(4.6 \%)$ & $57(4.4 \%)$ & $155(12 \%)$ \\
\hline Late & $126(9.7 \%)$ & 149(11.5\%) & $125(9.7 \%)$ & $400(30.9 \%)$ \\
\hline \multicolumn{5}{|l|}{ Dietary diversity score } \\
\hline$<4$ food groups & $334(25.8 \%)$ & $463(35.8 \%)$ & $421(32.5 \%)$ & $1218(94.1 \%)$ \\
\hline$\geq 4$ food groups & $13(1 \%)$ & $25(1.9 \%)$ & $39(3 \%)$ & $77(5.9 \%)$ \\
\hline
\end{tabular}

appropriately feed their children compared to housewife mothers. For that reason, sub-optimal breastfeeding and complementary feeding, the major risk factors of stunting are higher among outdoor worker mothers [41, 42]. However, a study in South Africa showed that children of outdoor worker mothers were less likely to be stunted [43]. That result suggested the positive effect of maternal employment in enhancing child nutritional status, mainly through improving household income, food security status, and utilization of health services [44, 45].

Surprisingly, higher odds of severe stunting were noted among children from households which accessing their food from farm (own production) compared to those from the households accessed their food through purchasing and donation. Though having a farm has its own role in improving e household food access [46], in many 
Table 5 An ordinal logistic regression showing the determinants of severe stunting among children aged 6-59 months in the predominantly rural population of northwest Ethiopia, 2015

\begin{tabular}{lll}
\hline Variable & Frequency & $\begin{array}{l}\text { Severe stunting } \\
\mathrm{n}(\%)\end{array}$
\end{tabular}

Number of under five children

1

101

2-4

1194

$21(20.8)$

Household size

$\begin{array}{llll}\leq 4 & 470 & 111(23.6) & 1 \\ 5-7 & 632 & 183(29) & 1.10(0.85,1.42) \\ 8-10 & 193 & 53(27.5) & 0.89(0.61,1.30)\end{array}$

Wealth status

Poor

489

187(38.2)

$2.07(1.56,2.75)^{\mathrm{a}}$

Medium

387

$90(23.3)$

Rich

419

$70(16.7)$

Main source of family food

$\begin{array}{llll}\text { Own production } & 886 & 263(29.7) & 1.44(1.09,1.89)^{\mathrm{a}} \\ \text { Purchasing } & 364 & 66(18.1) & 1 \\ \text { Others } & 45 & 18(40) & 1.74(0.94,3.23)\end{array}$

Maternal education

No formal education 884

Primary education $\quad 189$

Secondary education 222

Maternal employment status

$\begin{array}{ll}\text { Housewife } & 728 \\ \text { Farmer } & 351 \\ \text { Others } & 216\end{array}$

$256(29.0)$

54(28.6)

37 (16.7)

$1.24(0.85,1.79)$

$1.29(0.86,1.93)$

1

$167(22.9) \quad 1$

$146(41.6) \quad 1.45(1.08,1.93)^{\mathrm{a}}$

$34(15.7)$

$1.02(0.71,1.49)$

Paternal education

$\begin{array}{llll}\text { No formal education } & 864 & 254(29.4) & 1.08(0.84,1.40) \\ \begin{array}{l}\text { Formal education } \\ \text { Health care access }\end{array} & 431 & 93(21.6) & 1 \\ \text { Good } & 1148 & 295(25.6) & 1 \\ \text { Poor } & 147 & 52(35.4) & 1.38(0.99,1.91)\end{array}$

Source of drinking water

Unprotected source 794

$138(27.5)$

209(26.3)

Availability of latrine

$\begin{array}{llll}\text { Yes } & 387 & 93(24) & 1.15(0.90,1.48) \\ \text { No } & 908 & 254(28) & 1\end{array}$

Maternal vitamin A supplementation

$\begin{array}{llll}\text { Yes } & 305 & 59(19.3) & 1 \\ \text { No } & 990 & 288(29.1) & 1.54(1.19,2.00)^{\mathrm{a}}\end{array}$

Breastfeeding initiation within $1 \mathrm{~h}$

$\begin{array}{llll}\text { Yes } & 663 & 161(24.3) & 1 \\ \text { No } & 632 & 186(29.4) & 0.90(0.71,1.16)\end{array}$

Table 5 An ordinal logistic regression showing the determinants of severe stunting among children aged 6-59 months in the predominantly rural population of northwest Ethiopia, 2015 (Continued)

\begin{tabular}{|c|c|c|c|}
\hline Variable & Frequency & $\begin{array}{l}\text { Severe stunting } \\
\mathrm{n}(\%)\end{array}$ & $\mathrm{AOR}[95 \% \mathrm{Cl}]$ \\
\hline \multicolumn{4}{|c|}{ Exclusive breastfeeding } \\
\hline Yes & 808 & $180(22.3)$ & 1 \\
\hline No & 487 & 167(34.3) & $1.31(0.94,1.83)$ \\
\hline \multicolumn{4}{|c|}{ Complementary feeding initiation } \\
\hline Timely & 740 & 182(24.6) & 1 \\
\hline Early & 155 & $39(25.2)$ & $0.80(0.54,1.19)$ \\
\hline Late & 400 & $126(31.5)$ & $1.01(0.72,1.41)$ \\
\hline \multicolumn{4}{|l|}{ Dietary diversity score } \\
\hline$<4$ food groups & 1218 & $334(27.4)$ & $1.44(0.91,2.28)$ \\
\hline$\geq 4$ food groups & 77 & $13(16.9)$ & 1 \\
\hline
\end{tabular}

parts of Ethiopia farmers do not consume the produced food items, particularly animal based food stuff. In addition, almost all farmers living in rural areas of the country are more vulnerable to undernutrition [45].

To sum up, children whose mothers received no postnatal vitamin-A supplementation more odds of severe stunting than their counterparts. Improving vitamin-A status of children is one of the proven child survival strategies; it is found to especially reduce the risk of morbidity and mortality from infectious diseases [47, 48]. Frequent episodes of infectious diseases, such as diarrhea and respiratory tract infections are strongly associated with a higher risk of stunting [49]. In Ethiopia, most pregnant mothers suffer from vitamin-A deficiency [32], and have poor dietary intake of vitamin-A [4]. As a result, the postnatal period is a window of opportunity to improve mother's vitamin-A status thereby increasing the breast milk retinol level. This way, breastfed infants get an adequate amount of vitamin-A which further helps to reduce the risk of infectious disease episodes through boosting immunity.

\section{Conclusion}

Stunting is a severe public health problem in the predominantly rural northwest Ethiopia. Mother's occupation, postnatal vitamin-A supplementation, source of family food and household wealth status were identified as determinants of severe stunting. Therefore, emphasis should be given to improving maternal postnatal vitamin A supplementation coverage and building knowledge on appropriate feeding practices, particularly among farmer and poorer households.

Abbreviations

AOR: Adjusted Odds Ratio; Cl: Confidence Interval; COR: Crude Odds Ratio; DDS: Dietary Diversity Score; FANTA: Food and Nutrition Technical Assistance; 
HDSS: Health and Demographic Surveillance System; IYCF: Infant and Young Child Feeding; PCA: Principal Component Analysis; SD: Standard Deviation; WHO: World Health Organization

\section{Acknowledgements}

We would like to thank mothers for their willingness to participate in the study. Our appreciation will also go to the University of Gondar and Dabat DHSS site for their financial and material support, respectively.

\section{Funding}

This study was funded by the University of Gondar. The views presented in the article are of the author and not necessarily express the views of the funding organization. University of Gondar was not involved in the design of the study, data collection, analysis and interpretation.

\section{Availability of data and materials}

Due to ethical restrictions and privacy concerns, a dataset is available upon request from the author Amare Tariku at amaretariku15@yahoo.com.

\section{Authors' contributions}

AT GAB conceived the study, developed the tool, coordinated data collection, and carried out the statistical analysis and drafted the manuscript. TD MMW SMA conceived the study, participated in the statistical analysis, and drafted the manuscript. AT TD MMW conceived the study and review the drafted manuscript. All authors read and approved the final manuscript.

\section{Competing interest}

The authors declare that they have no competing interests.

\section{Ethics approval and consent to participate}

The study protocol was approved by Institutional Review Board (IRB) of the University of Gondar. The IRB waived the need for written informed consent, considering that the study did not involve any invasive procedures and reporting of any response for intervention. An official permission letter was secured from the Dabat HDSS site. Accordingly, all mothers were informed about the purpose of the study, and interview was held only with those who agreed to give verbal consent to participate. The right of a participant to withdraw from the study at any time, without any precondition was disclosed unequivocally. Moreover, the confidentiality of information was guaranteed by using code numbers rather than personal identifiers and by keeping the questionnaire locked.

\section{Consent for publication}

Not applicable.

\section{Publisher's Note}

Springer Nature remains neutral with regard to jurisdictional claims in published maps and institutional affiliations.

\section{Author details \\ 1 Department of Human Nutrition, Institute of Public Health, College of Medicine and Health Sciences, University of Gondar, Gondar, Ethiopia. ${ }^{2}$ Department of Health Service Management and Health Economics, Institute of Public Health, College of Medicine and Health Sciences, University of Gondar, Gondar, Ethiopia.}

Received: 5 September 2017 Accepted: 4 December 2017 Published online: 19 December 2017

\section{References}

1. Black RE, Victora CG, Walker SP, Bhutta ZA, Christian P, et al. Maternal and child undernutrition and overweight in low-income and middle-income countries. Lancet. 2013;382:427-51.

2. De Onis M, Brown D, Blossner M, Borghi E Levels and trends in child malnutrition. UNICEF-WHO-the World Bank joint child malnutrition estimates. 2012

3. Unicef. Improving child nutrition: the achievable imperative for global progress. New York: UNICEF; 2013.

4. Central Statistical Authority [Ethiopia] and ORC Macro. Ethiopia demographic and health survey 2011. Addis Ababa. Maryland: Ethiopia and Calverton; 2011.
5. Lasky RE, Klein RE, Yarbrough C, Engle PL, Lechtig A, et al. The relationship between physical growth and infant behavioral development in rural Guatemala. Child Dev. 1981;52:219-26.

6. Jesmin A, Yamamoto SS, Malik AA, Haque MA. Prevalence and determinants of chronic malnutrition among preschool children: a cross-sectional study in Dhaka City, Bangladesh. J Health Popul Nutr. 2011;29:494-9.

7. Moock PR, Leslie J. Childhood malnutrition and schooling in the Terai region of Nepal. J Dev Econ. 1986;20:33-52.

8. Grantham-McGregor S, Cheung YB, Cueto S, Glewwe P, Richter L, et al. Developmental potential in the first 5 years for children in developing countries. Lancet. 2007:369:60-70.

9. Onis $M$, Onyango A, Borghi E, Siyam A, Blössner $M$, et al. Worldwide implementation of the WHO child growth standards. Public Health Nutr. 2012;15:1603-10.

10. Kar BR, Rao SL, Chandramouli B. Cognitive development in children with chronic protein energy malnutrition. Behav Brain Funct. 2008;4:1.

11. WHO: Maternal, infant and young child nutrition..World Health Organization. 2011.

12. Asfaw $M$, Wondaferash $M$, Taha $M$, Dube $L$. Prevalence of undernutrition and associated factors among children aged between six to fifty nine months in Bule Hora district, South Ethiopia. BMC Public Health. 2015;15:1.

13. Fikadu T, Assegid S, Dube L. Factors associated with stunting among children of age 24 to 59 months in Meskan district, Gurage zone, South Ethiopia: a case-control study. BMC Public Health. 2014;14:1.

14. Agho KE, Inder KJ, Bowe SJ, Jacobs J, Dibley MJ. Prevalence and risk factors for stunting and severe stunting among under-fives in North Maluku province of Indonesia. BMC Pediatr. 2009;9:1.

15. Bwalya BB, Lemba M, Mapoma CC. Mutombo N (2015) factors associated with stunting among children aged 6-23 months in Zambian: evidence from the 2007 Zambia demographic and health survey. Int J of Adv Nutr Health Sci. 2015;3:116-31.

16. Rah J, Akhter N, Semba R, De Pee S, Bloem M, et al. Low dietary diversity is a predictor of child stunting in rural Bangladesh. Eur J Clin Nutr. 2010;64:1393-8.

17. Disha A, Rawat R, Subandoro A, Menon P. Infant and young child feeding (IYCF) practices in Ethiopia and Zambia and their association with child nutrition: analysis of demographic and health survey data. Afr J Food Agric Nutr Dev. 2012;12:5895-914.

18. Paudel R, Pradhan B, Wagle R, Pahari D, Onta S. Risk factors for stunting among children: a community based case control study in Nepal. Kathmandu Univ Med J. 2013:10:18-24.

19. Agedew E, Chane T. Prevalence of stunting among children aged 6-23 months in Kemba Woreda, southern Ethiopia: a community based crosssectional study. Adv Pub Health. 2015;2015.

20. Tamiru MW, Tolessa BE, Abera SF. Under nutrition and associated factors among under-five age children of Kunama ethnic groups in Tahtay Adiyabo Woreda. Tigray Regional State, Ethiopia: Community Based Study; 2015. p. 277-88.

21. Tariku A, Woldie H, Fekadu A, Adane AA, Ferede AT, et al. Nearly half of preschool children are stunted in Dembia district, Northwest Ethiopia: a community based cross-sectional study. Arch Pub Health. 2016;74:1.

22. Roger $\mathrm{S}$ and Yongyout K. "Analyzing the causes of child stunting in DPRK." 2003

23. El Taguri A, Betilmal I, Mahmud SM, Ahmed AM, Goulet O, et al. Risk factors for stunting among under-fives in Libya. Public Health Nutr. 2009;12:1141-9.

24. Black RE, Allen LH, Bhutta ZA, Caulfield LE, De Onis M, et al. Maternal and child undernutrition: global and regional exposures and health consequences. Lancet. 2008;371:243-60.

25. Tiwari R, Ausman LM, Agho KE. Determinants of stunting and severe stunting among under-fives: evidence from the 2011 Nepal demographic and health survey. BMC Pediatr. 2014;14:1.

26. Vitolo MR, Gama CM, Bortolini GA, Campagnolo PD, Drachler ML. Some risk factors associated with overweight, stunting and wasting among children under 5 years old. J Pediatr. 2008;84:251-7.

27. SM MK. Socio-economic determinants of severe and moderate stunting among under-five children of rural Bangladesh. Malays J Nutr.2011;17:105-18.

28. Chirande L, Charwe D, Mbwana H, Victor R, Kimboka S, et al. Determinants of stunting and severe stunting among under-fives in Tanzania: evidence from the 2010 cross-sectional household survey. BMC Pediatr. 2015;15:1.

29. Central Statistical Authority [Ethiopia] and ORC Macro. Mini Ethiopia demographic and health survey 2014. Addis Ababa. Maryland: Ethiopia and Calverton; 2014.

30. Federal Ministry of Health, Family Health Department Ethiopia. National strategy for infant and young child feeding. Addis Ababa: Federal Ministry of Health. Ethiopia: Family Health Department; 2004. 
31. Government of the Federal Democratic and Republic of Ethiopia: National Nutrition Program June 2013-June 2015.

32. Gebreselassie SG, Gase FE, Deressa MU. Prevalence and correlates of prenatal vitamin a deficiency in rural Sidama, southern Ethiopia. J Health Popul Nutr. 2013;31:185.

33. Cogill B. Anthropometric indicators measurement guide. 2003.

34. WHO, UNICEF. WHO child growth standards and the identification of severe acute malnutrition in infants and children: a joint statement by the World Health Organization and the United Nations Children's fund. Geneva: World Health Organization; 2009.

35. UNICEF WHO. Indicators for assessing infant and young child feeding practices. Part 1 definitions. Geneva: WHO; 2008.

36. Siddiqi A, Hertzman E, Irwin LG. Hertzman C early child development: a powerful equalizer. Improving equity in health by addressing social determinants; 2012. p. 115-41.

37. De Onis M, Blössner M, Borghi E. Prevalence and trends of stunting among pre-school children, 1990-2020. Public Health Nutr. 2012;15:142-8.

38. Thiombiano-Coulibaly N, Rocquelin G, Eymard-Duvernay S, Zougmore O. Traore $\mathrm{S}$ effects of early extra fluid and food intake on breast milk consumption and infant nutritional status at 5 months of age in an urban and a rural area of Burkina Faso. Eur J Clin Nutr. 2004;58:80-9.

39. Ricci JA, Becker $\mathrm{S}$. Risk factors for wasting and stunting among children in metro Cebu, Philippines. Am J Clin Nutr. 1996;63:966-75.

40. Mekonnen A, Jones N, Tefera B. Tackling child malnutrition in Ethiopia: do the sustainable development poverty reduction programme's underlying policy assumptions reflect local realities? 2005.

41. Biks GA, Tariku A, Tessema GA. Effects of antenatal care and institutional delivery on exclusive breastfeeding practice in northwest Ethiopia: a nested case-control study. Int Breastfeed J. 2015;10:1.

42. WHO. Infant and young child feeding: model chapter for textbooks for medical students and allied health professionals. 2009.

43. Willey BA, Cameron N, Norris SA, Pettifor JM, Griffiths PL. Socio-economic predictors of stunting in preschool children: a population-based study from Johannesburg and Soweto. S Afr Med J. 2009;99:450-6.

44. Crepinsek MK, Burstein NR. Maternal employment and children's nutrition. Economic Research Service. 2004. E-FAN No EFAN04006 Available online at http://www ers usda gov/publications/efan04006.

45. Girma W, Genebo T. Determinants of nutritional status of women and children in Ethiopia. 2002.

46. FAO. The state of food and agriculture Rome. 1994

47. UNICEF. A strategy for acceleration of progress in combating vitamin a deficiency. 1997.

48. Ezzati M, Lopez AD, Rodgers A, Murray CJ. Comparative quantification of health risks. Global and regional burden of disease attributable to selected major risk factors. Geneva: World Health Organization; 2004. p. 1987-97.

49. Pinstrup-Andersen P, Burger S, Habicht J-P, Peterson K. In: Jamison DT, Mosley WH, Measham AR, Bobadilla JL, editors. Protein-energy malnutrition. Disease control priorities in developing countries. Oxford: Oxford University Press; 1993. p. 391-420.

\section{Submit your next manuscript to BioMed Central and we will help you at every step:}

- We accept pre-submission inquiries

- Our selector tool helps you to find the most relevant journal

- We provide round the clock customer support

- Convenient online submission

- Thorough peer review

- Inclusion in PubMed and all major indexing services

- Maximum visibility for your research

Submit your manuscript at www.biomedcentral.com/submit

) Biomed Central 